\title{
Some new fixed point theorems in complete metric spaces
}

\author{
M. O. OlatinWo
}

\section{ABSTRACT.}

In this paper, we obtain some fixed point theorems for more general classes of mappings than the $A$-contractions of Akram et al. We also give an example of mappings satisfying our new class of contractive mappings but which does not satisfy the contractive condition of Akram et al. Our results generalize and extend the recent results of Akram et al., and unify several other classical results in the literature.

\author{
DEPARTMENT OF MATHEMATICS \\ OBAFEMI AWOLOWO UNIVERSITY \\ ILE-IFE, NigERIA \\ E-mail address: molaposi@yahoo.com; wo@oauife.edu.ng \\ E-mail address: memudu. olatinwo@gmail.com
}

Received: 09.11.2011; In revised form: 10.02.2012; Accepted: 31.07.2012

2010 Mathematics Subject Classification. 47H06, 54H25.

Key words and phrases. A-contractions, some fixed point theorems. 